\title{
Maternal and neonatal outcome in patients with vaginal birth after cesarean section (VBAC)
}

\author{
Mahantappa A Chiniwar, Sharada B Menasinkai \\ Correspondence: Dr Sharada B Menasinkai, Professor, Department of Anatomy, \\ Adichunchanagiri Institute of Medical Sciences Bellur, B G Nagara 571448, Tq \\ Nagamangala, Dist Mandya Karnataka, India; Email - drsharadabm@gmail.com \\ Distributed under Attribution-NonCommercial-ShareAlike 4.0 International (CC BY-NC-SA 4.0)
}

\begin{abstract}
Objective: The aim of study is to know the maternal and fetal outcome in the present pregnancy of patients with previous one caesarian section (CS). Methodology: A prospective study was undertaken to know the neonatal and maternal outcome in patients admitted with previous cesarean section for the period of $1 \mathrm{yr}$ and 9 months from October 1998 to June 2000. Vaginal delivery were monitored and failed trial cases were taken for repeat CS. Maternal and neonatal outcome was studied in the VBAC and repeat CS cases. Results: Among the total 14164 admissions to labour ward, there were 942 patients with previous CS (14.87\%). Elective CS was done for 530 cases and 412 cases were planned for trial of labour and out of them 311 had vaginal deliveries, with success of vaginal birth after cesarean (VBAC) of $75.48 \%$. There were 5 cases of rupture uterus and subtotal hysterectomy was done in 3 cases and closure of rent was done in 2 cases. Repeat CS was done in 96 cases. Neonatal outcome in VBAC babies was, $83.28 \%$ healthy, $7.72 \%$ had morbidity and admitted to neonatal intensive care unit (NICU) and $9 \%$ had mortality. Neonatal outcome in repeat CS were normal in 32.3\%, morbidity and admission to NICU was $41.66 \%$ with a mortality of $26.04 \%$. Maternal mortality occurred in 2 unbooked patients, 1 was associated with asthama and COPD, another with severe anemia with scar rupture. Conclusion: VBAC is more successful in cases with previous non recurrent indications. Vigilance regarding the indication of primary CS, proper patient selection and counseling for trial of scar, careful observation throughout in a well equipped unit are key to reducing CS rate.
\end{abstract}

Keywords: Cesarean section (CS), vaginal birth after cesarean section (VBAC), NICU, perinatal morbidity and mortality, subtotal hysterectomy.

Cesarean section (CS) is an operation mainly evolved to save a maternal life during difficult childbirth, has now become increasingly the procedure of choice in high risk situations to prevent neonatal morbidity and mortality. This alarming rise has been a matter of concern to the profession and public ${ }^{1}$. Planned vaginal birth after cesarean section (VBAC) is appropriate for and may be offered to the majority of women with singleton pregnancy of cephalic presentation at $37+0$ wks or beyond who have had previous lower segment cesarean delivery, with or without a history of previous vaginal birth ${ }^{2}$. VBAC is recommended after one CS, but preferably not after second CS, as it increases maternal morbidity and mortality. The rates of CS are rising all over the world.

Received: $23^{\text {rd }}$ July 2018. Accepted: $5^{\text {th }}$ October 2018.

Chiniwar MA, Menasinkai SB. Maternal and neonatal outcome in patients with vaginal birth after cesarean section

(VBAC). The New Indian Journal of OBGYN. 2019; 5(2): 99-102 
And India being a low resource country sometimes the poor families can't afford the CS. In primary health centers there may not be facilities available for fetal monitoring or for proving anaesthesia and there may be lack of trained personal. Vaginal delivery has less chances of infection, can be performed without general or spinal anaesthesia, provide early ambulation and early discharge, results in better bonding and early breast feeding ${ }^{2}$. Success of VBAC is around $72-75 \%$. Women should be informed that planned VBAC is associated with approximately 1 in $200(0.5 \%)$ risk of uterus rupture. Women should be informed of the two to three fold increased risk of uterine rupture and around 1.5 fold increased risk of cesarean delivery in induced and/or augmented labour compared with spontaneous VBAC labour ${ }^{2}$.

Cragin's dictum of "once a cesarean always a cesarean" contributed to $30-50 \%$ rise in cesarean rates in the United States, till $1980^{3,4}$. A series of studies in 1980 reported the relative safety of attempting VBAC. A large meta analysis showed a maternal mortality of 2.8 per 10,000 for women undergoing planned VBAC and 2.4 per 10,000 for women having an elective CS. Uterine dehiscence and rupture occur in less than $2 \%$ of planned VBAC, and percentage is same in women having an routine repeat CS. Perinatal mortality and morbidity rates were similar with the babies of women having planned VBAC and elective repeat CS. The present study was undertaken to know the maternal and fetal outcome in the present pregnancy of patients with previous one $\mathrm{C} \mathrm{S}$ in our hospital being a tertiary care center.

\section{Materials and Methods}

A prospective study was done for a period of 1 yr 9 months (Oct 1998 - June 2000) in Cheluvamba Hospital attached to Government Medical College Mysore.

This study has been done on patients admitted for safe confinement with previous history of CS.

Inclusion criteria were: All women with previous one lower segment cesarean section, cephalic presentation, live single fetus and gestational age between 37 to 40 wks.
Exclusion criteria were: All women with history of classical cesarean section, hysterotomy, myomectomy, more than one CS, abnormal presentation.

Detailed history of the patients were recorded in a proforma at the time of admission about previous CS, particulars regarding indications, post operative morbidity, weight of the baby and interval between previous section and present pregnancy. Women with $>4$ visits in our hospital were considered as booked cases and $<3$ visits and referred cases were considered as unbooked. History during present pregnancy, clinical examination findings, investigation reports were noted down. Women who were selected for trial of labour were carefully monitored for pulse, BP, uterine contractions, scar tenderness and progress of labour. $\mathrm{PGE}_{2}$ gel was used in few cases to induce labour. Artificial rupture of membrane (ARM) was done after $4 \mathrm{cms}$ of cervical dilatation and colour of liquor was noted to monitor the progress of labour. Oxytocin augmentation was done in cases when contractions were inadequate. Outlet forceps or ventouse delivery was done in indicated cases. Trial of labour was abandoned in few cases due to fetal distress, scar tenderness and threatened rupture and resorted to repeat CS. Modes of delivery were recorded in terms of spontaneous vaginal delivery, assisted delivery, instrumental delivery or CS. Postoperative findings of both mother and baby were noted. Results are presented in tables with numbers and percentage.

\section{Observations}

During the study period there were 14164 admissions to labour ward include 942 patients with previous CS

\begin{tabular}{|lcccc}
\hline Table 1: Percentage of previous cesarean section cases & & \\
\hline Previous history & $\begin{array}{l}\text { Total } \\
\text { of cases }\end{array}$ & $\begin{array}{l}\text { Vaginal } \\
\text { deliveries }\end{array}$ & $\begin{array}{l}\text { Cesarean } \\
\text { section }\end{array}$ & $\begin{array}{l}\text { \% of } \\
\text { LSCS }\end{array}$ \\
\hline Primigravida and & & & & \\
previous normal delivery & 13222 & 11756 & 1476 & 11.16 \\
Previous LSCS & 942 & 311 & 631 & 66.98 \\
\hline Total & 14164 & 12062 & 2107 & 14.87 \\
\hline
\end{tabular}

(table 1), and out of them 586 (56.9\%) were booked and 356 (37.79\%) were unbooked. Among 942 patients with previous CS, elective CS was done for 530 cases and 412 cases were selected for trial of labour. Vaginal birth 
conducted in 311 cases, and repeat CS was decided for 101 cases. Success of VBAC was $75.48 \%$. Table 2 is showing the indications for primary CS in VBAC cases.

\begin{tabular}{lll}
$\begin{array}{l}\text { Table 2: Indications for primary } \\
\text { cases }(\mathbf{N}=\mathbf{3 1 1})\end{array}$ & S in VBAC \\
\hline Indications & No. of cases & Percentage \\
\hline Fetal distress & 58 & 18.64 \\
Breech & 32 & 10.28 \\
Transverse lie & 30 & 9.64 \\
CPD & 31 & 9.96 \\
PROM & 30 & 9.64 \\
Cervical dystocia & 20 & 6.43 \\
PIH & 18 & 18 \\
Deep transverse arrest & 10 & 3.21 \\
Placenta previa & 10 & 3.21 \\
Unknown & 72 & 23.04 \\
\hline
\end{tabular}

Among the VBAC, most of the cases induction of labour was done (48.87\%) (table 3). Among the 412 trial of labour cases, 5 cases had rupture uterus and subtotal

Table 3: mode of delivery in VBAC cases no 311

\begin{tabular}{lll}
\hline Mode of delivery & Number of cases & $\mathbf{\%}$ \\
\hline Spontaneous & 100 & 32.17 \\
Assisted labour & 152 & 48.87 \\
(ARM,+oxytocin) & & \\
Forceps delivery & 43 & 13.82 \\
Ventouse & 16 & 5.14 \\
\hline Total & 311 & 100 \\
\hline
\end{tabular}

hysterectomy was done for 3 cases and closure of the rent in 2 cases. In the study repeat CS was done in 96 cases. Table 4 is showing percentage of indications for repeat CS in the study.

Neonatal outcome in VBAC cases - 259 healthy babies, 40 babies required admission to NICU and neonatal mortality in 12 babies. The causes of perinatal mortality were, intra uterine death -3 , prematurity -6 , congenital malformations

Table 5: Perinatal outcome in VBAC

\begin{tabular}{llllll}
\hline Baby status & \multicolumn{2}{l}{ Present study } & \multicolumn{2}{l}{ Sharma A et al } & \multicolumn{2}{l}{ Akanksha N et al $^{4}$} \\
\hline Healthy & $259(83.27 \%)$ & 25 & $(89.28 \%)$ & 23 & $(100 \%)$ \\
Morbidity & $40 \quad(12.87 \%)$ & 3 & $(0.96 \%)$ & 0 & \\
Mortality & $12(3.85 \%)$ & 0 & $(0 \%)$ & 0 & \\
\hline Total & 311 & 28 & & 23 & \\
\hline
\end{tabular}

3. The perinatal outcome of 96 repeat C S babies were healthy 31 babies, morbidity in 40 babies who required NICU admission and mortality in 25 babies. The causes for mortality were intra uterine death -2 , prematurity -11 , others- 12 .
Maternal outcome in VBAC cases, morbidity was seen in 21 cases, second degree perineal tear- 3 , post partum haemorrhage -3 , scar dehiscence -3 , rupture uterus seen

Table 4: Indications for repeat cesarean section in failed trial of labour cases (96)

\begin{tabular}{lll}
\hline Indications & Number of cases & $\mathbf{\%}$ \\
\hline Fetal distress & 50 & 52.08 \\
Scar tenderness & 14 & 14.58 \\
Cervical dystocia & 12 & 12.50 \\
Failed induction & 8 & 8.33 \\
Deep transverse arrest & 12 & 12.50 \\
\hline Total & 96 & 100 \\
\hline
\end{tabular}

in 5 cases, and subtotal hysterectomy done in 3 and closure of rent in 2 case. Maternal mortality was seen in 2 unbooked cases 1 due to asthama with COPD and another case due to severe anemia and scar rupture.

\section{Discussion}

There is a wide spread public and professional concern about the increasing proportions of birth by CS world wide ${ }^{3,4}$. Increasing rates of primary CS have led to an increased proportion of obstetric population who have a history of prior cesarean delivery. Pregnant women with previous CS may be offered either a trial for VBAC or an elective repeat CS. Proportion of women who decline VBAC, is in turn a significant determinant of overall rates of cesarean births ${ }^{3,4}$.

The overall rate of repeat of VBAC as reported in literature, varies from $28-51 \%{ }^{4,5}$. The sample size in the present study was 412 and out of them 311 had VBAC giving a $75.46 \%$. Sharma A et al ${ }^{1}$ reported $27.45 \%$, Uma Pandey et $\mathrm{al}^{2}$ reported $61.76 \%$, Anagha A et $\mathrm{al}^{3}$ reported
$26.56 \%$, Akanksha Nigam et al ${ }^{4}$ reported $23 \%$, Manikya Rao et $\mathrm{al}^{5}$ reported $48 \%$ and Astha Lalwani et al ${ }^{6}$ reported $71 \%$. Present study is comparable with the study by Astha Lalwani et al ${ }^{6}$. 
In the present study the most common indication $52.08 \%$ for repeat CS was fetal distress, $25 \%$ for cervical dystocia and deep transverse arrest. To compare the results with other studies, Sharma A et al ${ }^{1}$ reported fetal distress in $28.37 \%$ and non progress of labour in $22.97 \%$, Uma Pandey et al ${ }^{2}$ reported $53.84 \%$ for fetal distress and $10 \%$ for failure to progress, Anagha $\mathrm{A}$ et $\mathrm{al}^{3}$ reported $52.88 \%$ for fetal distress, Akanksha Nigam et al ${ }^{4}$ reported $62.9 \%$ for fetal distress and $18.5 \%$ nonprogress of labour and Manikya Rao et $\mathrm{al}^{5}$ reported over all $80 \%$ for fetal distress and non progress of labour. Present study is comparable with the study reported by Akanksha $\mathrm{N}$ et al ${ }^{4}$ and Manikya Rao et $\mathrm{al}^{5}$.

Scar dehiscence defined as disruption of uterine muscle with intact serosa, was seen in $1.06 \%$ in the present study, The $\%$ of scar dehiscence in other studies, Anagha $\mathrm{N}$ et $\mathrm{al}^{3}$ reported $2.75 \%$,Akanksha $\mathrm{N}$ et $\mathrm{al}^{4}$ reported $7.4 \%$ seen intra operatively during repeat CS. and Manikya Rao et $\mathrm{al}^{5}$ reported 2\%. Rupture of the uterus was seen in 5 patients among trial of labour in the present study (1.21\%), and subtotal hysterectomy was done in 3 and closure of the rent in 2 cases and repeat CS was done for 96 cases. Percentage of rupture uterus $0.98 \%$ in a study reported by Sharma A et $\mathrm{al}^{1}$.

Maternal morbidity following VBAC in the present study was second degree perineal tear $0.73 \%$, PPH $0.73 \%$, MRP was done for $0.48 \%$. Comparing with other studies, Uma Pandey et al ${ }^{2}$ reported pyrexia $7.1 \%$, blood transfusion done for $7.1 \%$, urinary tract infection (UTI) $7.1 \%$, episiotomy infection in $7.1 \%$, Anagha $\mathrm{A}$ et $\mathrm{al}^{3}$ reported pyrexia $5.53 \%$, blood transfusion $3.4 \%$, UTI $2.55 \%$, Manikya Rao et $\mathrm{al}^{5}$ reported $23.07 \%$ overall morbidity. Maternal mortality rate in the present study was $0.42 \%$, there were no mortality in study reported by, Anagha $\mathrm{N}$ et al ${ }^{3}$, Akanksha $\mathrm{N}$ et al ${ }^{4}$.

Perinatal outcome in VBAC cases is compared with other studies (table 5). In the present study morbidity is more indicating NICU admissions. Perinatal mortality in the study is due to IUD (5), congenital malformations (5) and 2 babies stillbirth.

\section{Conclusion}

It is essential to counsel the patients with the history of prior cesarean section, ideally during antenatal period, regarding the benefits and risks of VBAC, enabling them to make informed choice early and probably bring down the repeat cesarean section rate. Induction is safe in selected cases oxytocin is effective and is recommended in response to standard obstetric indication. However $\mathrm{PGE}_{2}$ induction/augmentation needs caution. In properly selected women VBAC can constitute safe form of management._In absence of severe morbidity associated with scar dehiscence following a trial for VBAC and with low maternal and perinatal morbidity, vaginal deliveries are much safer outcome than repeat CS.

\section{Conflict of interest: None. Disclaimer: Nil.}

\section{References}

1.Sharma A. Sharma U. Chudhary P. Acharya R. Choudhary A. Hanspal J. Maternal and Neonatal outcome in Patients with History of Previous One Cesarean Section. Indian Medical Gazette. May 2012: 169-73.

2.Pandey U, Tripathy P. Success of VBAC in a Tertiary Hospital. J of Gynaecology and Women's Health. 2017; 2(1): JGWH.MS.ID.555577.

3.Jinturkar AA, Dongaonkar D. Study of Obstetric and Fetal Outcome of Post Cesarean Section Pregnancy at Tertiary Care Center. International $\mathrm{J}$ of Recent Trends in Science And Technology. 2014; 10(3): 530-7.

4.Nigam A, Anand R, Jain N. Study of obstetric and fetal outcome of post cesarean pregnancy. International $\mathrm{J}$ of Reproduction, Contraception, Obstetric and Gynaecology. 2015 Feb; 4(1): 215-18.

5.Rao SM, Sravanti S, Sandhy A. Maternal and Fetal Outcome Following Trial of Labour after Previous Cesarean Section (Tolac). IOSR. Journal of Dental and Medical Sciences (IOSR JDMS). 2016; 15(1): 71 -6.

6.Lalwani A, Nagam R. A Clinical Study on Prospect of Vaginal Birth in Post Cesarean Pregnancy. Annals of International Medical and Dental Research. 2017; 3(5): 1-4.

\footnotetext{
Mahantappa A Chiniwar ${ }^{1}$, Sharada B Menasinkai ${ }^{2}$

${ }^{1}$ Professor, Department of Obstetrics and Gynaecology; ${ }^{2}$ Professor, Department of Anatomy; Adichunchanagiri Institute of Medical Sciences Bellur B G Nagara 571448, Tq Nagamangala, Dist Mandya Karnataka, India.
} 